\title{
Art Design Theory Education in Colleges and Universities
}

\author{
Xiangguo Ge \\ Jiang xi Institute of Fashion Technology \\ Nanchang, Jiang xi, China 330201
}

\begin{abstract}
The art design theory course, as an integral part of art teaching, is well known by a great number of people. However, with the speed of the marketing process, more and more people think practical skills are more important than theory. Aimed at the status quo, the author emphasizes the importance of art and design theory, through putting forward some feasible suggestions on this issue that will help the students' long-term development.
\end{abstract}

Keywords-theory course; importance; the status quo; advice

\section{INTRODUCTION}

In our country, art design education is divided into three parts: design basis courses, design theory courses, and professional design. Design theory courses, as compulsory course of design major, has its inherent systemic and integrity. It not only contains the design of cultural heritage, it also includes the system of art and design experience. Through knowledge accumulation, students can use the knowledge to design their reasonable imagination. This is an essential part of the teaching system. Art design theory as a foundation for design course is not allowed to neglect its basic position. Only learning the basic theoretical knowledge well can use the theoretical knowledge to guide practice. We can design works by inspiration, practitioners of hands-on ability. But the design is not simply imitate and copy; it is the original creation. If you want the students to create original pieces, you need to learn design theory knowledge to fully absorb, digest and research the past basic knowledge. Then, you can lay a good foundation for future innovation. In order to find the objective laws of art and design, the essence behind it, the students must learn a art design theory knowledge,. So art design education should not only teach the techniques, skills, and at the same time should also be taught "ways", emphas is on teaching them to "fishing" rather than "fish". ${ }^{[1]}$ Art design theory course do not cultivate art workers or artisan, but it trains a person who has theoretical accomplishment and can find the problem, analyze it, and solve.

The teaching purpose decides the teaching content and the teaching method, but art design theory courses' teaching purpose is to make students not only master the culture, art, design theory knowledge, but to also enable students to master the essential rule. The students can break through the basic rules and get new opinions. It also can improve the students' professional, cultural, moral, cultural and other aspects of culture.

\section{The CURRENT Situation OFthe ART DESIGN THEORY COURSE}

\section{A. Now Many Students Think the Theory of Art Design Courses is not Important}

This phenomenon reflected that the students think skill or practice is more important than theory. The reason is various: 1. In art design course, students prefer to quickly bring designs from the design practice lesson, and theory are relatively dull, and tend to be abstract theory concept and stronger logic. It has a certain difficulty and pressure. It cannot cause the students' interest, so at last it is difficult to cause the attention of the students; 2 . From the demand of the market, especially the needs of the enterprise, now a lot of enterprises in the process of recruitment, only consider the candidate's design ability, regardless of the students' theoretical knowledge. So the students pay more attention on social practice and despise theory. [2] 3. Colleges and universities are paying more and more attention to the employment rate, in such an environment, the school also unconsciously to design practice, thus ignore the supervision of theory course, from the teacher to the students with indifferent attitude to the theory, and theory of art design. So it is also the results of the environment affection. ${ }^{[3]}$

\section{B. The Art Design Theory Curriculum is not Science}

Because in the professional art colleges and universities, most schools pay attention to the design practice lesson, so the design theory curriculums are not arranged very reasonably (e.g. less class hours and more content). The system of the theory of art design courses is not perfect enough. Some schools theory don't accord to discipline rules and have a lack of organization. They don't use the rule that the theory to guide the reality. The courses don't have any reality significance. In order to complete the course arrangement of the so-called "rigid demand", some schools even freely placed the theory "sail" in practice class or in the time of concentration "MVP". It is easy to cause the students think theory dispensable.

\section{The Teaching Method is not Reasonable}

In many universities, though the technology is developed quickly, many teachers don't change their methods. They only transfer the content from the book or blackboard to the 
PPT. Such teaching methods make the teacher in class without passion, and students also have no interest in class. Moreover teachers don't conform to the development of contemporary times, unable to stimulate the enthusiasm of the students in the classroom and raise their interest.

\section{THE IMPROVEMENT MEASURES OF ART DESIGN THEORY COURSES}

People Should Constantly Change Ideas. Paying more attention to the art design theory, we will have an incentive to learn art design theory. We also should remember that art design theory is the foundation and originality of art design. Only fully understanding the nature of design principles and objective laws, understand the social, cultural knowledge, can display their own thought emotion, humanistic care and reflect the vitality of works. [4]

In the Setting of a Course, We Need to Understand and Grasp the Nature of Art and Design Theory.If we want to set the curriculum science, we must draw lessons from foreign theory of institutions, taking its essence to its dregs. It makes the theory of art design course setup tend to be more reasonabl so that the students can study better.

On the teachers, we not only should improve the teachers practice design ability but also improve the teachers professional learning of theoretical knowledge. Because a teacher only have comprehensive quality, they must improve on it so they can guide their students better. Art teachers not only master the art practice but also professional theory knowledge. Such a teacher will let student feel that teacher is a real college teacher, and that kind of teachers can cultivate the students.

On the reform of teaching method, we can discuss from these aspects.

- We will make the combination of theory and art design practice. In theory lessons, the teachers can join the practice appropriately. For example, teachers can decorate some simple practical design activities, use the theory to guide the design works, and have discussions in class. Through discussion, we can understand another's learning methods and design concept. The teachers also can let students visit museums, increasing the students' extracurricular experience. After visiting, let the students write about something that they experienced in a museum. Also, the designer is tested need to walk into society, can undertake university-enterprise cooperation, teachers with students visit to the enterprise, or summer and winter vacation to go to practice in enterprises for better combination of theory and practice.

- Through a variety of teaching forms, improve the students' interest in theory. For example, in the beginning of the lesson, the teacher can according to the main content of the class, in the form of a story begins to mobilize the classroom atmosphere. Whether ancient or modern, we can see from the building to the building reflects the social background, the humanities culture and so on, this will certainly arouse the enthusiasm of the students. [5] In the classroom, we should make full use of modern multimedia, through using pictures and animation, changing the form of pure words about before. Let the students more specifically learning knowledge, using a combination of words and pictures can be better to teach the content. Teachers also can put some video about teaching content. This may decrease the students' feeling of drabness and to enjoy the theory courses. Use tabular form to facilitate students' memory can improve the learning theory efficiency. To make design works creative and vital, the art design major students need to know the importance of the art theory design, realize the importance of learning theory curriculum knowledge, learn from theory course, find the objective rules of art design education, and summarize the essence of art design behind the phenomenon. By improving the current situation of art design, emphasizing art design theory importance, setting the theoretical courses reasonable, strengthening the teachers team construction, and improving teaching methods can make a design theory is more and more popular among students.

\section{REFERENCES}

[1] Ming-Yu Liu. Theory of art design education in colleges and universities think [J]. Journal of academic BBS, 2010 (6).

[2] Zhao Hui. History of university undergraduate course design in the art design education curriculum setting and teaching $[\mathrm{J}]$. Journal of arts education, 2012 (8).

[3] Yu-Fen Li. Introduction to the current situation of art design in colleges and universities gave birth to learn art theory [J]. Journal of chifeng institute, 2012 (9).

[4] Xiao-Hong Zeng. Theory of institutions of higher learning of art design education study [J]. Journal of xiangtan normal university, 2006 (4).

[5] Xiao-Hua Chen. The comparative study of Chinese and western design philosophy [D]. Hunan university, 2002. 